\title{
Using Tablet Devices and Social Media in a Course about the 2012 US Election Campaign
}

Paul R. Brewer, University of Delaware

Ralph J. Begleiter, University of Delaware

Katherine Anderson, University of Delaware

Meredith Isaacs, University of Delaware

ABSTRACT The use of both tablet devices and social media is increasingly popular among the American public. With this in mind, this article discusses our use of the technologies in a course about the 2012 US election campaign. We provided all students in our course with an iPad, created a private Facebook group, and devised a variety of approaches for integrating the technologies into the course. Surveys at the beginning and the end of the course showed that students frequently used their iPad for political and instructional purposes and that their self-confidence in using tablet devices, apps, and social media for political purposes increased during the semester. Open-ended responses and our own observations also suggest that use of the technologies fostered active online conversations about course material. In particular, use of the iPad and the Facebook group in combination during in-class video screenings, guest speakers, and debates facilitated lively, creative interactions among students and between students and instructors.

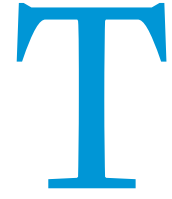

he popularity of both mobile devices and social media has expanded dramatically in recent years. Surveys indicate that ownership of tablet devices such as an iPad grew from $3 \%$ of US adults in May 2010 to 25\% in September 2013 (Brenner 2013). Surveys also show that usage of social networking sites among Internet users more than doubled from 29\% in May 2008 to $72 \%$ in May 2013; as of December 2012, fully 67\% used Facebook, the most popular such site (Pew Research Center 2013). Thus, it is no surprise that Americans increasingly use mobile technology (Mitchell et al. 2012) and social media (Caumont 2013) to follow public affairs.

Paul R. Brewer is associate director for research at the Center for Political Communication, professor of communication, and professor of political science and international relations at the University of Delaware. He can be reached at prbrewer@udel.edu.

Ralph J. Begleiter is founding director of the Center for Political Communication, Rosenberg Professor of Communication, and Distinguished Journalist in Residence at the University of Delaware. He was CNN's world affairs correspondent during the network's first two decades. He can be reached at ralph.begleiter@udel.edu.

Katherine Anderson received her MA in communication from the University of Delaware. She can be reached at ander@udel.edu.

Meredith Isaacs received her MA in communication from the University of Delaware She can be reached at misaacs@udel.edu.
Furthermore, Americans often use them in conjunction with one another to follow and communicate about politics, including electoral campaigns (Smith and Duggan 2012).

As the use of these new technologies has expanded, so has research on using tablet devices (e.g., Mang and Wardley 2012; Morris, Ramsey, and Chauhan 2012) and social media (e.g., Moran, Seaman, and Tinti-Kane 2011; Roblyer et al. 2010) in higher education. Findings suggest that the technologies in question can produce beneficial educational outcomes, if they are used under the appropriate conditions. Looking at political science education in particular, one study demonstrates the benefits of using iPads to deliver course readings (Marmarelli and Ringle 2012); another study suggests the benefits of using social bookmarking (Lightfoot 2012).

Considering these results, this article discusses our use of tablet devices and social media in a course about the 2012 US election campaign. We provided all of our students in the course with an iPad, created a private Facebook group, and devised a variety of approaches for integrating these technologies into the course. In conjunction with the course, we conducted a study to discover how students used the iPads and the Facebook group; how their technological self-efficacy (i.e., their confidence in their ability to use technology; see Lim 2001) changed during the semester in 
regard to tablet devices, tablet and smartphone "apps," and social media; and how they perceived the advantages and disadvantages of the technologies in the context of the course. Given the extensive evidence that it promotes learning (e.g., Bandura 1993), we gave particular attention to self-efficacy; specifically, technological self-efficacy can predict learning in courses using information technology (e.g., Johnson, Hornick, and Salas 2008; Simmering, Posey, and Piccoli 2009). We also were interested in whether the technologies facilitated course-related conversations within as well as outside of class meetings. To answer these questions, we conducted surveys at the beginning and at the end of the course. Based on the results and our observations of students' activity through the Facebook group during and outside of class meetings, we offer insights on how political science instructors might use tablet devices and social media.

\section{THE COURSE}

The course titled "Road to the Presidency 2012" was team-taught by two professors at a Mid-Atlantic public university during the fall of 2012. The overarching goal was to foster not only knowledge of but also active, critical engagement with and dialogue about the campaign. The course focused on the presidential campaign; however, it also included material on campaigns for Congress and statewide elected offices. It addressed numerous facets of campaigning, including the historical context, campaign finance (specifically the influence of the Citizens United decision and Super PACs), nomination process, party conventions, gerrymandering, televised debates, television advertising, news coverage, polling (including the rise in poll aggregators, such as Nate Silver's FiveThirtyEight blog), roles of factions such as the Tea Party, and interpretation of election results and exit polls (including patterns across demographic divides along sex, race, ethnicity, region, and age). in good condition). ${ }^{1}$ We instructed them to install 23 preselected "apps" (including the Facebook application) and encouraged them to install any other apps of their choice. Each student received a gift card to cover the expense of purchasing the apps. ${ }^{2}$ We also prearranged for bolstered networking capabilities in our classroom to support the technical challenge of the intense use of more than three dozen Wi-Fi devices.

To provide a social-media forum for the course, we created a private Facebook group visible only to class members and from which postings could not emanate to other Facebook users. This procedure did not require students or instructors to "friend" one another, which prevented instructors from viewing nonclassrelated postings by students elsewhere on Facebook. We allowed students who did not want to join under their personal Facebook account to join under an account created especially for the course.

In using the course technologies, we sought a balance between requiring students to engage in specific activities and allowing them freedom to explore, as well as between face-to-face and technology-mediated interaction. We required students to bring their iPad to all class meetings, including those with guest speakers and other "live" events. We used the AudienceOpinion app to conduct frequent in-class polls and then discussed the results. We also required every student to post at least one comment per week on the Facebook page (e.g., a link or an image with their own analysis) and to respond substantively to at least one other student's comment per week. During regular "lecture" class sessions, we typically emphasized face-to-face conversations. However, we also encouraged students to post comments to the private Facebook page during in-class video screenings of campaign ads and documentary clips, speaker events and debates that they attended, and presidential debates (one of which the class watched together at a special session).

\section{In using the course technologies, we sought a balance between requiring students to engage in specific activities and allowing them freedom to explore, as well as between face-to-face and technology-mediated interaction.}

The course used a variety of approaches, including required readings from textbooks and the New York Times, lectures, class discussion, and video screenings (e.g., television ads and excerpts from debates and documentaries such as The War Room). The class met twice a week but the coursework also incorporated extensive outside activities, including required attendance at guest-speaker events (i.e., the speakers included politicians, political-communication experts, and journalists) and a series of "live" political debates featuring candidates for elected offices (i.e., governor, lieutenant governor, US senator, and US representative). Students took weekly quizzes about news events (focusing on the assigned New York Times coverage), conducted group projects, and completed midterm and final exams.

Of the 39 students, 14 were honors students and 2 were graduate students (the latter helped conduct the research described here). Given the nature of this elective course, the students who enrolled were predisposed to be highly engaged and motivated.

At the beginning of the semester, each student received an iPad to use for the duration of the course (all were returned

\section{METHODS}

To assess the students' use of and response to the iPad and Facebook page, we conducted on online survey of the course's 37 undergraduate students at the beginning of the semester and another online survey at the end of the semester. Both surveys were voluntary and anonymous. ${ }^{3}$ A total of 29 students completed the "pretest" and 34 completed the "posttest." Among the respondents, women (62\% pretest; $53 \%$ posttest) outnumbered men (38\% pretest; $47 \%$ posttest). Most respondents self-identified as white ( $82 \%$ pretest; $78 \%$ posttest), with the remainder identifying as either Asian/Pacific islander ( $9 \%$ pretest; $5 \%$ posttest) or not self-identifying on race. Ages ranged from 19 to 22 in both surveys. Democrats (42\% pretest; $56 \%$ posttest) outnumbered Republicans (18\% pretest; $24 \%$ posttest) and independents ( $27 \%$ pretest; $21 \%$ posttest).

\section{RESULTS}

The pretest revealed that $66 \%$ of the respondents had previously used a tablet device but that only $14 \%$ owned one. Thus, having full-time access to a tablet device was a new experience for most 
students. The posttest showed that respondents frequently used their iPad for political and instructional purposes (table 1). Of the respondents, $59 \%$ reported using their iPad at least once a day to find information about political campaigns. A smaller yet sizable percentage (44\%) used it to communicate with others about political campaigns at least once a day. The same percentage (44\%) used their iPad to communicate with classmates about their courses at least once a day. Respondents did not use their iPad as frequently to communicate with their instructors; nevertheless, $56 \%$ reported doing so at least a few times a week.

A comparison of pretest and posttest results suggests that self-efficacy in using the technologies for political purposes increased during the course (table 2). Self-confidence in using tablet devices to find information about political campaigns significantly increased, as did self-confidence in using such devices to communicate with others about political campaigns. A similar pattern emerged for self-confidence in using apps for each activity. Respondents did not report increased selfconfidence in using social media sites to find information about political campaigns, but they did report increased selfconfidence in using these sites to communicate with others about political campaigns. Mean posttest levels were high for each item (i.e., around 3 or greater on a 4 -point scale, indicating "confident").

The pretest did not include items measuring self-confidence in using the technologies for instructional purposes. However, the posttest results suggest high levels of self-efficacy (i.e., around 3 or greater) for using tablet devices to communicate with instructors and classmates about courses and for using apps and social media to communicate with classmates about courses.

Table 1

\section{Students' Uses of iPads (Posttest Results)}

\begin{tabular}{|c|c|c|c|c|c|c|c|}
\hline Activity & 4+ times /day & 2-3 times /day & Once /day & Few times /week & Once /week & < Once /week & Never \\
\hline $\begin{array}{l}\text { Finding information about political } \\
\text { campaigns }\end{array}$ & $15 \%$ & $32 \%$ & $12 \%$ & $27 \%$ & $6 \%$ & $9 \%$ & $0 \%$ \\
\hline $\begin{array}{l}\text { Communicating with others about } \\
\text { political campaigns }\end{array}$ & $9 \%$ & $18 \%$ & $18 \%$ & $24 \%$ & $15 \%$ & $15 \%$ & $3 \%$ \\
\hline $\begin{array}{l}\text { Communicating with classmates } \\
\text { about your courses }\end{array}$ & $18 \%$ & $18 \%$ & $9 \%$ & $27 \%$ & $18 \%$ & $3 \%$ & $9 \%$ \\
\hline $\begin{array}{l}\text { Communicating with instructors } \\
\text { about your courses }\end{array}$ & $0 \%$ & $9 \%$ & $9 \%$ & $38 \%$ & $12 \%$ & $12 \%$ & $21 \%$ \\
\hline
\end{tabular}

Notes: $\mathrm{N}=34$. Due to rounding, some rows do not total $100 \%$.

Table 2

Pretest and Posttest Measures of Technological Self-Efficacy

\begin{tabular}{|c|c|c|c|}
\hline & Pretest & Posttest & $t$ \\
\hline \multicolumn{4}{|c|}{$\begin{array}{l}\text { In general, how self-confident would say you feel in using tablet devices such as } \\
\text { iPads to do the following activities: }\end{array}$} \\
\hline Finding information about political campaigns & $2.83(1.03)$ & $3.56(0.61)$ & $3.47^{* *}$ \\
\hline Communicating with others about political campaigns & $2.59(1.02)$ & $3.41(0.82)$ & $3.33^{* *}$ \\
\hline Communicating with classmates about your courses & - & $3.35(0.81)$ & - \\
\hline Communicating with instructors about your courses & - & $3.09(0.93)$ & - \\
\hline \multicolumn{4}{|c|}{$\begin{array}{l}\text { In general, how self-confident would say you feel in using tablet or smartphone } \\
\text { "apps" to do the following activities: }\end{array}$} \\
\hline Finding information about political campaigns & $2.83(0.97)$ & $3.47(0.75)$ & $2.98^{* *}$ \\
\hline Communicating with others about political campaigns & $2.52(1.02)$ & $3.09(0.97)$ & $2.28^{*}$ \\
\hline Communicating with classmates about your courses & - & $2.97(0.97)$ & - \\
\hline Communicating with instructors about your courses & - & $2.71(1.06)$ & - \\
\hline \multicolumn{4}{|c|}{$\begin{array}{l}\text { In general, how self-confident would say you feel in using social media sites such } \\
\text { as Facebook to do the following activities: }\end{array}$} \\
\hline Finding information about political campaigns & $3.00(0.96)$ & $2.94(0.94)$ & 0.26 \\
\hline Communicating with others about political campaigns & $3.00(0.90)$ & $3.44(0.76)$ & $2.04^{*}$ \\
\hline Communicating with classmates about your courses & - & $3.34(0.90)$ & - \\
\hline Communicating with instructors about your courses & - & $2.75(1.05)$ & - \\
\hline $\mathrm{N}$ & 29 & 34 & \\
\hline
\end{tabular}


Respondents reported somewhat lower levels of self-efficacy for using apps and social media sites to communicate with instructors.

The number of required apps that respondents used "regularly" ranged from zero to 20 , with a median of 8 . The most frequently mentioned apps were RealClear Politics (21), the Washington Post (14), Facebook (13), AudienceOpinion (11), the New York Times (10), Twitter (8), and CNN (8)-all of which were required.

Pretest open-ended comments about the advantages of using an iPad in the course frequently mentioned the potential for "easy" and "immediate" access to information and news. A number of comments highlighted how "small," "lightweight," "portable," or "mobile" an iPad is relative to a laptop. Other comments mentioned the availability of useful apps, including campaign-specific apps. One common theme in pretest comments about disadvantages was the potential for "overwhelming" "information overload" in the face of a "constant stream of information" and "constant pressure to stay updated." Another common theme was the potential for distraction, particularly for personal versus course uses.

The posttest comments about advantages reflected the pretest themes of access to information, mobility relative to laptops,
The instructors and teaching assistants independently observed extensive "after-hours" course-related activity by the students. Late into the night, our students routinely were using the private Facebook group, trading commentary, observations, opinions, and discoveries about the unfolding campaign and our in-class discussion. Many (but not all) students used the Facebook forum in excess of the minimal posting requirements, and several engaged in rich, substantive discussion-often pointing out examples from the ongoing campaign of concepts raised in class.

\section{CONCLUSION}

When we provided access to tablet devices and a social media forum as part of a course about an election campaign, our students took advantage of the technologies. These students, most of whom had never owned a tablet device, frequently used their iPad to engage with politics, their classmates, and their instructors. Moreover, the students' self-confidence in using tablet devices, apps, and social media to engage in political activities increased from the beginning of the semester to the end. In discussing the course technologies in their own words, students highlighted the benefits of using them to interact with one another and their instructors, particularly during "live events."

\section{In discussing the course technologies in their own words, students highlighted the benefits of using them to interact with one another and their instructors, particularly during "live events."}

and availability of useful apps. Many comments also highlighted themes that reflected specific ways in which we used the iPads, apps, and social media in the course. One respondent wrote, "I think that the use of iPads in class was extremely effective-i.e., using the iPads for surveys, to look up polls, and to post comments about lectures on the Facebook page." Similarly, another student wrote, "It made the class much more interactive-some of the best classes were when videos were on and everyone was in the [Facebook] group posting and commenting; that made the class feel much more alive. Also nice to see both professors join in with posts and comments." A third student wrote, "Being able to see everyone's live reactions to speakers." A fourth commented, "I enjoyed the 'AudienceOpinion' [polls] a lot. I think that sparked a lot of good discussion."

In regard to disadvantages of the iPad, several respondents said there were none (e.g., one student wrote, "Having to give it back!"). However, a number of posttest comments echoed pretest concerns about distraction. One respondent wrote, "At times I found it fascinating to communicate with my classmates and instructors about a speaker's remarks 'live,' but often I felt like I was missing integral parts of their lecture." Likewise, another respondent commented, "It was a double-edged sword-they were useful to have in class, while at the same time I think they may have caused some distraction amongst various students, taking away from their overall comprehension of the lecture." A few respondents cited technical issues involving screen size, navigation, and lack of prior familiarity with Apple products. Several viewed the iPad as redundant, given that they already owned a smartphone and/or a laptop.
Our personal observations from teaching the course dovetail with the last of these points. From our viewpoint, the most striking and transformative uses of the technologies flowed from using the iPad and the Facebook group in combination. We witnessed the conversations among students-and between students and instructors-on the Facebook group grow livelier over time. This was especially evident during the in-class video screenings, guest speakers, and debates, during which students used their iPad to post dozens of comments and replies within an hour or two. During a class session on campaign advertising, for example, students posted observations about historical ads that they likely would not have raised verbally; one student admitted online that she was unaware of the famous 1964 "Daisy" ad and others remarked on how contemporary ads echoed techniques of the past. In other examples, students used the Facebook forum during "live" events to conduct their own "fact-checks" and to argue or agree with speakers. In the face of time constraints-and potential student deference to respected speakers-the Facebook/iPad combination allowed our students to engage in extensive interaction through the "back channel" provided by the technology.

Interaction on the Facebook group became more informal and creative over time, as students and instructors grew more at ease with one another and more familiar with the technologies. For example, students began creating and posting witty, self-generated Internet "memes" (i.e., captioned pictures) during class events. They also posted occasional snarky comments about the speakers' statements and even about their instructors. Along with more serious postings, these contributions created a more engaged class atmosphere.

To be sure, our findings also point to potential disadvantages of using iPads and social media in a course setting-particularly 
the potential for distraction that students highlighted in their own comments. Such distraction could interfere with student learning of the course material (Mang and Wardley 2012). Furthermore, what worked in our course would not necessarily be appropriate in every course. Our course extensively incorporated outside-the-classroom events that sparked some of the most active uses of the technology, and it played out against the broader backdrop of a presidential election cycle. By the same token, our students-many of whom were honors students and all of whom enrolled in an unusually demanding course with a special incentive of the iPad loan-may have invested atypical time and energy in using the technologies. The students in the class were relatively experienced (i.e., almost all were juniors or seniors); accordingly, first-year students might require more guidance. Our students also were demographically unrepresentative; thus, "digital divides" may have implications for applying our experiences to other courses.

In the appropriate situations, however, tablet devices and social media in the classroom can be a catalyst for a more engaged, "connected," and interactive learning experience that extends beyond the actual classroom. This conclusion echoes previous findings that new technologies can produce beneficial outcomes when used strategically (e.g., Mang and Wardley 2012). Based on our experience, we believe that the technologies in question can be especially helpful when used in combination and when actively and continuously integrated into a course through approaches such as in-class polling and "live" commenting on events. Although some observers have raised concerns about whether the advantages of online interactions match those of face-to-face interactions (e.g., Putnam 200o), a growing body of research attests to the potential educational (Lightfoot 2012) and democratic benefits (Ellison, Steinfield, and Lampe 2007) of interactions through social media. Furthermore, the use of mobile devices and social media in political science education may cultivate technological self-efficacy. This is important given the potential effects of technological self-efficacy on learning outcomes (Johnson, Hornick, and Salas 2008; Simmering, Posey, and Piccoli 2009) and the growing role of mobile technology and social media in political campaigns. Cultivating technological self-efficacy seems to be potentially viable in a wide range of courses. Further study could explore whether promoting such efficacy can expand knowledge, interest, and engagement in public affairs among young people beyond election cycles-which, in turn, could contribute more broadly to democratic society.

\section{NOTES}

1. Funding for this project reflected collaboration between the University of Delaware's Center for Political Communication and its Information Technologies services (which provided a grant through a competitive program).
2. The required apps were Ad Hawk, AP Mobile, AudienceOpinion, CNN, CNN Time Convention Pass, The Daily Show, eClicker Audience, Facebook, Flipboard, Fox News, Huffington Post, New York Times, The Onion, Pinterest, Pulse, RealClear Politics, Show of Hands, Super PAC App, Twitter, USA Today, Wall Street Journal, Washington Post Politics, and You Decide 2012 Map.

3. Given that we conducted the surveys while the course was in progress, we made them anonymous and voluntary on both ethical (i.e., avoiding coercion) and methodological (i.e., avoiding socially desirable responses) grounds.

\section{REFERENCES}

Bandura, Albert. 1993. "Perceived Self-Efficacy in Cognitive Development and Functioning." Educational Psychologist 28 (2): 117-48.

Brenner, Joanna. 2013. "Pew Internet: Mobile." Available at http://pewinternet.org/ Commentary/2012/February/Pew-Internet-Mobile.aspx.

Caumont, Andrea. 2013. "12 Trends Shaping Digital News." Available at http://www.pewresearch.org/fact-tank/2013/10/16/12-trends-shaping-digital-news.

Ellison, Nicole B., Charles Steinfield, and Cliff Lampe. 2007. "The Benefits of Facebook 'Friends': Social Capital and College Students' Use of Online Social Networks." Journal of Computer-Mediated Communication 12 (4): 1143-68.

Johnson, Richard D., Steven Hornick, and Eduardo Salas. 20o8. "An Empirical Examination of Factors Contributing to the Creation of Successful e-Learning Environments." International Journal of Human-Computer Studies $66(5): 356-69$

Lightfoot, Simon. 2012. "Delicious' Politics: The Use of Social Bookmarking in Politics Teaching." Journal of Political Science Education 8 (1): 94-101.

Lim, Christina Kyounghee. 2001. "Computer Self-Efficacy, Academic Self-Concept, and Other Predictors of Satisfaction and Future Participation of Adult Distance Learners." American Journal of Distance Education 15 (2): 41-51.

Mang, Colin F., and Lesley J. Wardley. 2012. "Effective Adoption of Tablets in Post-Secondary Education: Recommendations Based on a Trial of iPads in University Classes." Journal of Information Technology Education 11: 301-17.

Marmarelli, Trina, and Martin Ringle. 2012. "The Reed College iPad Study.” Available at http://www.reed.edu/cis/about/ipad_pilot/Reed_ipad_report.pdf.

Mitchell, Amy, Tom Rosenstiel, Laura Houston Santhanam, and Leah Christian. 2012. "Future of Mobile News." Available at http://www.journalism.org/2012/ 10/o1/future-mobile-news.

Moran, Mike, Jeff Seaman, and Heather Tinti-Kane. 2011. "Teaching, Learning, and Sharing: How Today's Higher Education Faculty Use Social Media." Available at http://files.eric.ed.gov/fulltext/ED535130.pdf.

Morris, Neil P., Luke Ramsey, and Vikesh Chauhan. 2012. "Can a Tablet Device Alter Undergraduate Science Students' Study Behavior and Use of Technology?" Advances in Physiology Education 36 (2): 97-107.

Pew Research Center. 2013. "Social Networking Use." Available at http://www. pewresearch.org/data-trend/media-and-technology/social-networking-use.

Putnam, Robert D. 200o. Bowling Alone: The Collapse and Revival of American Community. New York: Simon and Schuster.

Roblyer, M. D., Michelle McDaniel, Marsena Webb, James Herman, and James Vince Witty. 2010. "Findings on Facebook in Higher Education: A Comparison of College Faculty and Student Uses and Perceptions of Social Networking Sites." The Internet and Higher Education 13 (3): 134-40.

Simmering, Marcia J., Clay Posey, and Gabriele Piccoli. 2009. "Computer Self-Efficacy and Motivation to Learn in a Self-Directed Online Course." Decision Sciences: Journal of Innovative Education 7 (1): 99-121.

Smith, Aaron, and Maeve Duggan. 2012. "The State of the 2012 Election: Mobile Politics." Available at http://web.pewinternet.org/Reports/2012/ Election-2012-Mobile/Overview.aspx. 